\title{
Attenuated GLP-1 secretion in obesity: cause or consequence?
}

\author{
L R Ranganath, J M Beety, L M Morgan, J W Wright, R Howland, V Marks
}

\begin{abstract}
Background-Hypersecretion of insulinotropic factors such as glucose dependent insulinotropic polypeptide (GIP) and glucagon-like peptide-1(7-36)amide (GLP1) have been postulated to account for the hyperinsulinaemia of obesity.

Aims-To examine the role of GLP-1 and GIP in obese women and matched controls.

Subjects-Six lean and six obese women subjects matched for age.

Methods-The gut hormone, plasma glucose, and serum triglyceride responses were studied over 180 minutes after oral carbohydrate and fat meals. Heparin (10 000 units) was given intravenously at 120 minutes.

Results-There was pronounced attenuation of plasma GLP-1 secretion to oral carbohydrate in the obese compared with lean subjects but no such difference in response to oral fat load. There were no differences in the plasma GIP responses to carbohydrate or fat feeding. There was an apparent fall in plasma GLP-1 values in all subjects after administration of heparin.

Conclusion-Postprandial GLP-1 secretion in response to oral carbohydrate is considerably attenuated in obese subjects. The cause of this attenuation of GLP-1 secretion is not known although we suggest that both this fall and the overall reduction in GLP-1 values in obese subjects may be related to an increase in plasma non-esterified fatty acids.

(Gut 1996; 38: 916-919)
\end{abstract}

Keywords: GLP-1, obesity, carbohydrate meal, fat meal.

Obesity is often associated with impaired glucose tolerance, insulin resistance as well as fasting and postprandial hyperinsulinaemia. ${ }^{12}$ Generally, insulin secretion after food intake is the net effect of a direct stimulation by absorbed nutrients, as well as indirect stimulation by neural and humoral signals. Insulinotropic gastrointestinal factor, referred to as 'incretin', was first described in 1929 by Zunz and LeBarre, and proof for this concept was provided in 1964 by McIntyre et al when they showed that insulin response is far greater after oral glucose administration, than after the intravenous route. ${ }^{34}$ Over the years, various candidates for the 'incretin factor' have been examined, including glucose dependent insulinotropic polypeptide (GIP), which strongly stimulates insulin secretion after carbohydrate, fat, and mixed meals. ${ }^{5}$ Molecular biology techniques have shown that posttranslational processing of proglucagon in the pancreas and ileum yields several novel glucagon-like peptides. ${ }^{67}$ Among these, the truncated fragment of GLP-1 (hitherto called GLP-1 in this paper), has been shown to be strongly insulinotropic and its secretion has been shown to increase after oral glucose and mixed meals. ${ }^{8}{ }^{9}$ In addition to its insulinotropic effect, GLP-1 inhibits pancreatic glucagon secretion, decreases hepatic gluconeogenesis, and decreases insulin resistance. 1011

It has been postulated that an exaggerated 'incretin' factor may have a pathophysiological role in obesity. A role for GIP has been examined in this regard but has not been conclusively shown. ${ }^{5}$ In this context, it has been suggested that hypersecretion of GLP-1 may be the long sought 'incretin' factor in obesity. ${ }^{12}$ Indeed, Fukase and colleagues have examined this hypothesis in a study where they showed increased secretion of glucagon-like peptide-1 in obese diabetic subjects but the responses in non-diabetic obese and matched controls were very similar.

However, the methodology adopted by Fukase and workers for GLP-1 assay was indirect and less specific than that used in this study and included GLP-1(7-37), which is normally present at very low concentrations in plasma, and the two biologically inactive major proglucagon derived fragments. GLP-1(736)amide, measured in this study, is the predominant circulating molecular species of glucagon-like peptides in humans. We undertook this study to clarify the conclusions of Fukase and colleagues that hypersecretion of GIP and GLP-1 is characteristic of the obese state.

\section{Methods}

\section{Subjects}

Six obese premenopausal women and six sex and age matched lean controls were recruited. The mean (SD) age of obese and lean subjects was $30.2(10.7)$ and $31.0(9.5)$ years respectively. The mean (SD) body mass index (BMI), calculated as the ratio of body weight in kilograms to that of height in metres square, was $40 \cdot 1(8 \cdot 0)$ (range $31 \cdot 8-48 \cdot 3$ ) and $21 \cdot 3$ $(0.83)$ (range $20.0-23.6)$ respectively in obese and lean. Waist:hip ratio of lean and obese groups showed a mean (SD) of $0.72(0.03)$ and $0.80(0.08)$ respectively.

Ethical committee approval (at Royal Surrey County Hospital, Guildford, Surrey) for the 

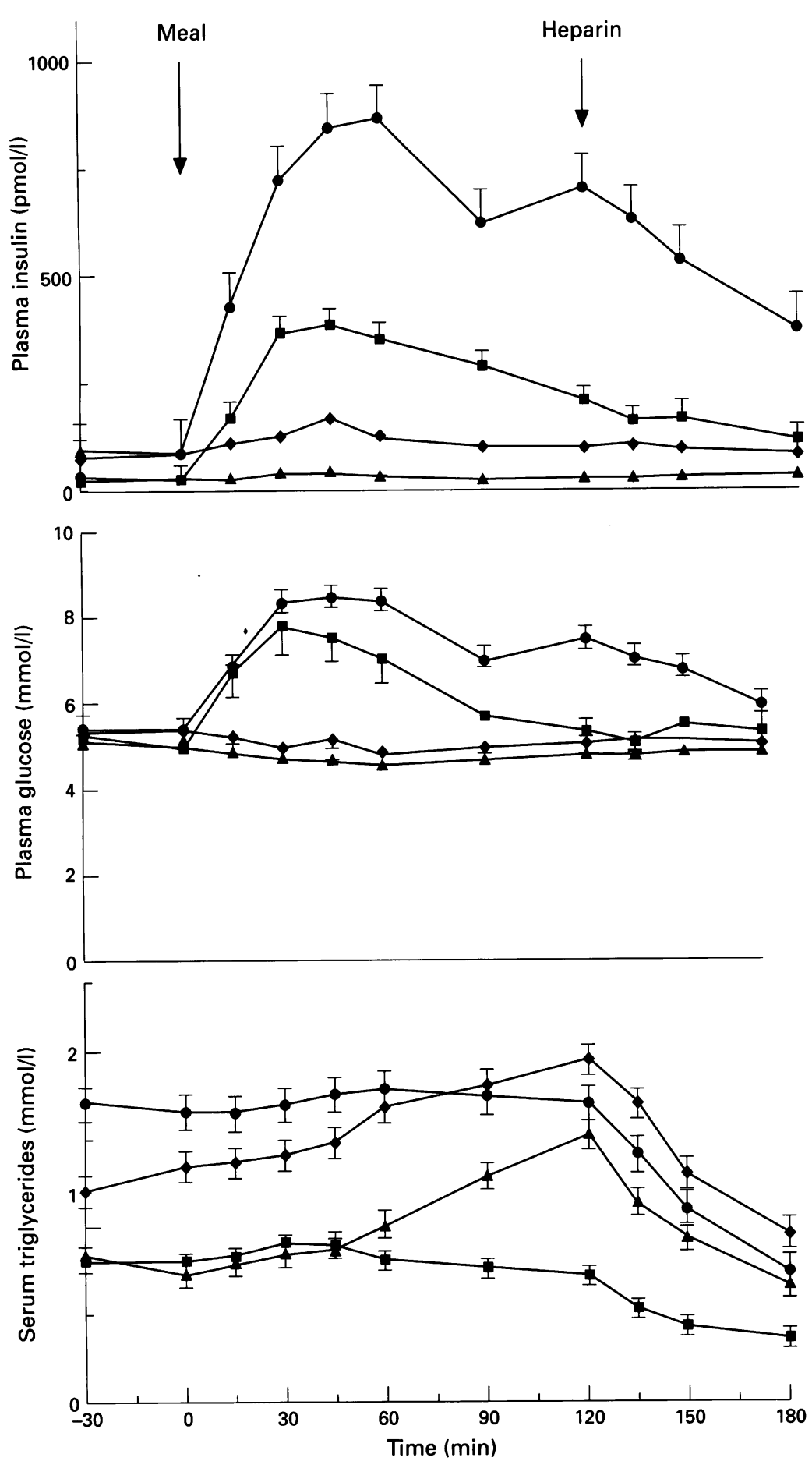

Figure 1: Insulin, glucose, and triglyceride values after oral carbohydrate or fat in lean and obese subjects. The mean (SEM) $(n=6)$ of carbohydrate meal in lean ( $)$ and obese (O) subjects as well as of fat meal in lean ( $\boldsymbol{\Delta})$ and obese $(\bullet)$ subjects are shown.

study had been obtained and each subject gave written consent before participation. All subjects were in good health and not taking any medication. Three of the obese subjects were smokers and none of the subjects consumed more than 10 units of alcohol per week. All lean and obese subjects were requested not to follow a weight reducing diet for the duration of the study; no other restrictions were imposed.

\section{Study design}

Subjects were studied on two separate days, each separated by a period of a week. On each study day they attended the Clinical
Investigation Unit at the Royal Surrey County Hospital at 0830 after an overnight fast. Subjects were given in random order an equicaloric $(340 \mathrm{kcal})$ oral load of either carbohydrate (Hycal $100 \mathrm{~g}$, Smith-Kline Beecham diluted $1: 1$ by volume with water) or fat (Sainsbury's Double Cream, 37.8 g diluted 1:1 by volume with water). Blood samples $(15 \mathrm{ml})$ were obtained through an indwelling forearm intravenous cannula before the carbohydrate/ fat load ( -30 and 0 minutes) and at intervals for a further period of 180 minutes after the load. An intravenous bolus of heparin 10000 units was given two hours after the carbohydrate/fat loads on each occasion to assess lipoprotein lipase activity described elsewhere. ${ }^{13}$ Blood samples were collected into fluoride/oxalate and lithium heparin bottles for measurement of glucose and hormones (insulin and GIP) respectively. Samples for GLP-1 were collected into lithium heparin bottles containing aprotinin $(1000 \mathrm{KIU} / \mathrm{ml}$ of blood). Blood samples were collected into plain glass bottles for triglyceride analyses. All plasma samples were separated immediately and both plasma and serum samples were stored frozen at $-25^{\circ} \mathrm{C}$ until analysis.

\section{Chemical analysis}

Glucose and triglycerides were measured by glucose oxidase (Olympus reagents, analysed on Olympus AU 5000 analyser) and lipase chemical reactions linked to coupled enzyme assay systems (Olympus reagents, analysed on Olympus AU 5000 analyser) respectively on appropriate samples. Insulin ${ }^{14}$ and GIP $^{15}$ were analysed by radioimmunoassay using iodinated label and polyethylene glycol accelerated double antibody precipitation by methodology described in detail elsewhere.

The GLP-1 radioimmunoassay in this study has been previously described ${ }^{16}$ and uses an antiserum raised in a rabbit against GLP-1 (736)amide. It crossreacts $100 \%$ with GLP-1 (136)amide but shows negligible crossreactivity with GLP-1(1-37), GLP-1(7-37), glucagon, and major proglucagon fragment. ${ }^{125}$ I-labelled GLP-1 was affinity purified on a solid phase, consisting of rabbit anti-GLP-1 antibodies coupled to silica beads, on the day of its addition into assay tubes. Lyophilised synthetic GLP-1 standards prepared inhouse were used in the assay. Phase separation was effected by dextran coated charcoal. Interassay coefficient of variation at GLP-1 concentrations of $15 \cdot 4$, $29 \cdot 4$, and $33.5 \mathrm{pM}$ were $17 \cdot 4,14 \cdot 1$, and $13.4 \%$ respectively. Intra-assay coefficient of variation at GLP-1 concentrations of $10 \cdot 3,19 \cdot 3$, and 24 pM were $13,10 \cdot 1$, and $9 \cdot 3 \%$ respectively.

\section{Statistical analysis}

Response profiles were compared by one way analysis of variance and specific differences between groups were identified using Duncan's multiple range test. Total and incremental areas under the curve were calculated using the trapezoidal rule. $p$ Values of $<0.05$ were considered significant. 


\section{Results}

Figure 1 shows the glucose, triglyceride, and insulin responses to the test meals. The peak plasma glucose concentrations after oral carbohydrate were significantly higher in the obese $(p<0.01)$ as was the area under the curve ((mean incremental area under the curve (SD) (IAUC) 389 (198) $\mathrm{mM} / \mathrm{min}$ ) (0-180 $\mathrm{min}$ ) in obese when compared with lean subjects (IAUC $169(89) \mathrm{mM} / \mathrm{min})(\mathrm{p}<0.01)$ ). Fasting serum triglycerides were higher in obese subjects $(p<0.01)$ but after the oral fat load, the incremental area under the curve was similar in the two groups (IAUC (SD) of 65 (9) and 45 (12) $\mathrm{mM} / \mathrm{min}$ in lean and obese respectively). There was no change in the plasma triglyceride values after the oral carbohydrate load. A decline in serum triglyceride concentrations after the administration of heparin was seen in both groups (Fig 1). The mean fasting plasma insulin concentrations and insulin responses to carbohydrate meal were higher in the obese subjects (IAUC (SD) was $42(3.9)$ and 112 (17) $\mathrm{pM} / \mathrm{min}$ for lean and obese respectively) $(\mathrm{p}<0.05$ and $\mathrm{p}<0.01$ respectively) (Fig 1).

Figure 2 shows the plasma GLP-1 responses to the test meals. The mean fasting plasma concentration of GLP-1 before administration of oral carbohydrate was lower in obese subjects $(p<0.05)$, but no such difference in the fasting GLP-1 concentrations were noted before administration of oral fat. The mean peak plasma GLP-1 response to carbohydrate occurred at 15 minutes and 90 minutes in the obese and lean respectively. Incremental GLP1 responses under the curve $(0-180 \mathrm{~min})$ to carbohydrate were considerably lower in the obese $(\mathrm{p}<0.01)$ (IAUC (SD) was $4.8(1.5)$ and
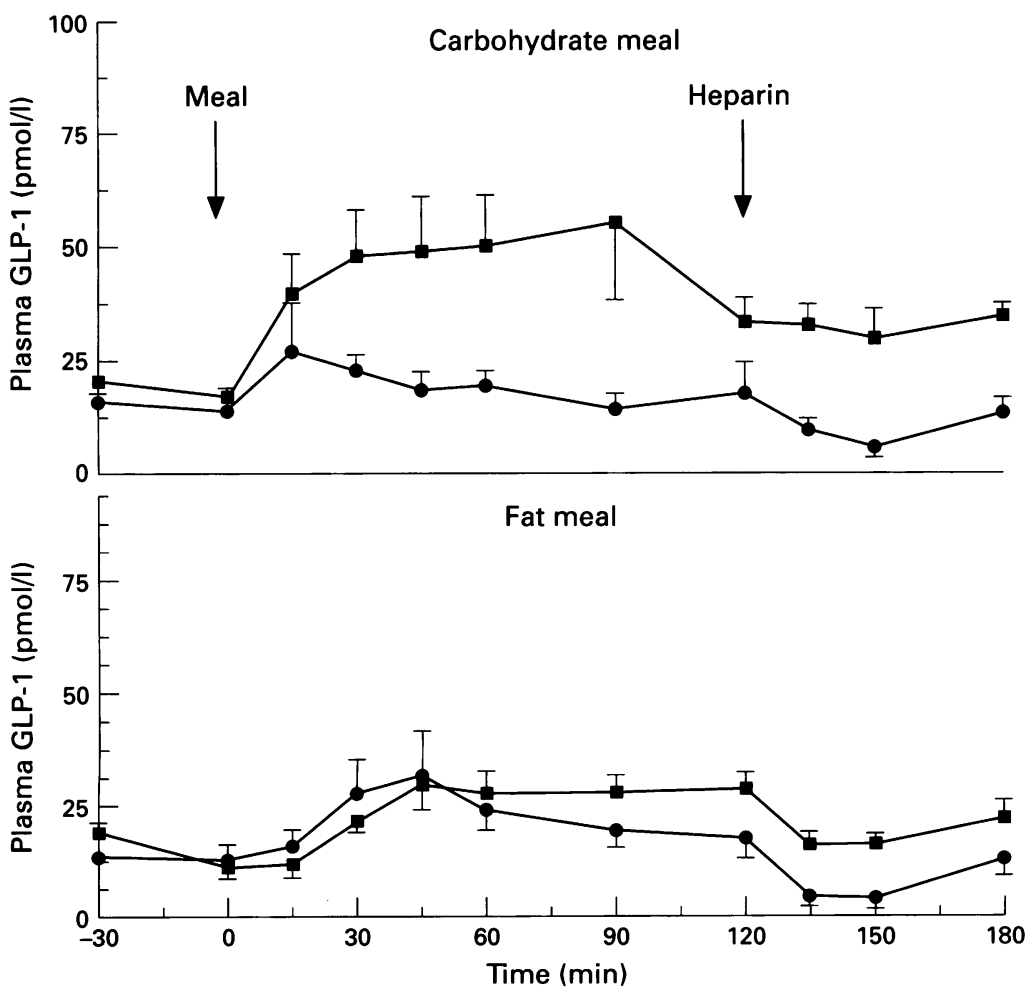

Figure 2: Plasma GLP-1 responses to oral carbohydrate and fat in lean and obese subjects. The mean (SEM) $(n=6)$ of plasma GLP-1 in lean ( $\square$ ) and obese (O) subjects are shown.
$0.3(0.4) \mathrm{pM} / \mathrm{min}$ for lean and obese respectively). There was a decline in plasma concentration of GLP-1 at 150 minutes, 30 minutes after administration of heparin, in both lean and obese subjects when compared with those at 120 minutes $(\mathrm{p}<0 \cdot 01)$.

Plasma GIP concentrations were similar in lean and obese after carbohydrate and fat meals (IAUC (SD) for carbohydrate meals was 41 (5) and $39(5 \cdot 3) \mathrm{pM} / \mathrm{min}$ respectively in lean and obese; IAUC (SD) for fat meals was $46(7 \cdot 4)$ and $44(4 \cdot 2) \mathrm{pM} / \mathrm{min}$ respectively in lean and obese) (Fig 3).

\section{Discussion}

This study confirms the finding that, after ingestion of both carbohydrate and fat, there is a prompt rise in the plasma concentrations of GLP-1.17 The greatest rise in GLP-1 concentrations was seen after carbohydrate in lean subjects; in the obese, this rise was considerably attenuated. There was, however, no such difference between lean and obese subjects after a fat stimulus.

After carbohydrate, the obese subjects also showed less efficient glucose disposal and higher plasma insulin concentrations. The GIP response to carbohydrate feeding was similar in the two groups, while the GLP-1 response was lower in the obese. This study does not, therefore, lend support to the suggestion that oversecretion of either GIP and GLP-1 may participate in the hyperinsulinaemia of obesity. Rather, as GLP-1, in addition to its insulinotropic action, has been shown to increase peripheral insulin sensitivity, ${ }^{11}$ it is possible that the lower GLP-1 response to carbohydrate seen in the obese subjects may have a role in the pathogenesis of the peripheral insulin resistance characteristic of obesity.

Fasting hyperinsulinaemia and exaggerated postprandial responses to oral carbohydrate was seen in obese subjects. We did not find any difference in GIP response between lean and obese groups and this excludes a role for an increased 'incretin' effect of GIP as the cause of hyperinsulinaemia of obesity. As discussed previously, this study was undertaken to clarify the findings of Fukase and workers who found increased GLP-1 in obese mildly diabetic subjects but GLP-1 responses that were similar in non-diabetic obese and lean matched controls. ${ }^{12}$ Indeed, it could be argued that as neither GIP nor GLP-1 were increased in the obese subjects in this study, the hyperinsulinaemia of obesity may be the consequence of insulin resistance and that insulin resistance may be more important as the cause of obesity.

Plasma GLP-1 concentrations seemed to decrease after administration of heparin in both obese and lean subjects. Although we do not have data on GLP-1 secretion after oral carbohydrate without heparin in this study, previous work in our department has shown that the decline is GLP-1 noted in this study does not occur in lean subjects when oral carbohydrate is given without heparin. ${ }^{16} \mathrm{We}$ considered possible reasons for reduced GLP-1 secretion in the obese and the apparent decline 


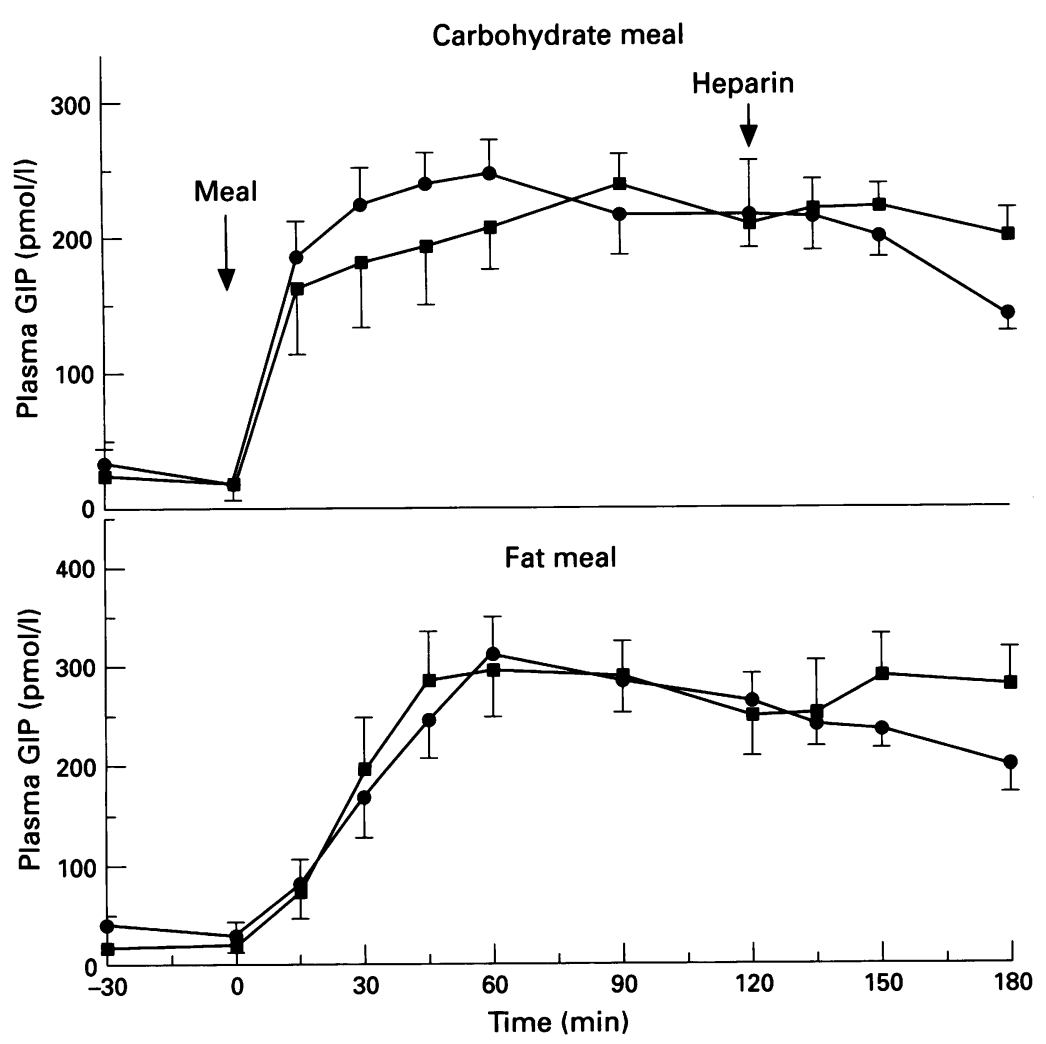

Figure 3: Plasma GIP responses to oral carbohydrate and fat in lean and obese subjects. The mean (SEM) $(n=6)$ of plasma GIP in lean ( () and obese (O) subjects are shown.

in GLP-1 after heparin in all subjects after both meals. We considered the possibility that decline after heparin may result from a direct effect of heparin on GLP-1 secretion or to increasing plasma concentrations of nonessential fatty acid released by heparin administration (with parallel decrease in serum triglycerides). As the fall of GLP-1 after heparin was unanticipated, GLP-1 concentrations after glucose load without heparin administration were not measured and the postulated effect of non-esterified fatty acids on GLP-1 remains speculative. We suggest that, although not measured in this study, raised plasma non-esterified fatty acid concentrations, which are known to be associated with obesity ${ }^{1819}$ may be the cause for the blunted
GLP-1 response to carbohydrate and for the further decline in plasma GLP-1 that follows heparin administration.

1 Inoue S. Metabolic effects of autonomic nervous activity in development of obesity (ventromedial obesity). In: Oomura Y, et al, eds. Progress in obesity research. London: John Libbey, 1990: 95-101.

2 Bailey CJ, Flatt PR. Animal models of diabetes. In: Nattrass $\mathrm{M}$, ed. Recent advances in diabetes. Edinburgh: Churchill $M$, ed. Recent advances in

3 Zunz E, LeBarre J. Contributions a l'etude des variations physiologiques de la secretion interne du pancreas: relations entre les secretions externe et intern du pancreas. Arch Int Physiol Biochem 1929; 31: 20-44.

4 McIntyre N, Holdsworth DC, Turner DS. New interpretation of oral glucose tolerance. Lancet 1964; ii: $20-1$.

5 Morgan LM. Insulin secretion and the enteroinsular axis. In: Flatt $\mathrm{P}$, ed. Nutrient regulation of insulin secretion. London: Portland Press, 1992: 1-22.

6 Bell GI, Sanchez-Pescador R, Laybourn PJ, Najarian RC. Exon duplication and divergence in the human preproglucagon gene. Nature 1983; 304: 368-71.

7 Bell GI, Santerre RF, Mullenbach GI. Hamster preproglucagon contains the sequence of glucagon and two proglucagon contains the sequence of gluces

related peptides. Nature 1983; 302: 712-8.
8 Holst J, Orskov G, Nielsen OV, Schwartz. Truncated glucagon-like peptide 1, an insulin-releasing hormone from the distal gut. FEBS Lett 1987; 211: 169-74.

9 Kreyman B, Williams G, Ghatei MA, Bloom SR. Glucagonlike peptide-1 (7-36): A physiological incretin in man. Lancet 1987; ii: $1300-3$.

10 Orskov C, Wettergren A, Holst JJ. Biological effects and metabolic effects of glicagon-like peptide-1 7-36 amide and glucagon-like peptide-1 7-36 in healthy subjects are indistinguishable. Diabetes 1993; 42: 658-61.

11 Gutniak M, Orskov C, Holst JJ, Ahren B, Efendic S. Antidiabetogenic effect of glucagon-like peptide-1 (7-36) amide in normal subjects and patients with diabetes amide in normal subjects and patients with

12 Fukase N, Igarashi M, Takahashi H, Manaka H, Yamatani $\mathrm{K}$, Daimon $\mathrm{M}$, et al. Hypersecretion of truncated Kl Daimon $M$, et al. Hypersecretion of truncated in obese patients. Diabet Med 1993; 10: 44-9.

13 Beety JM. The role of gastrointestinal hormones in the deposition and mobilisation of lipids in adipose tissue. PhD Thesis. Guildford: University of Surrey, 1994.

14 Hampton SM. C peptide of proinsulin: its diagnostic use and possible physiological role. $\mathrm{PhD}$ Thesis. Guildford: University of Surrey, 1984

15 Morgan LM, Morris BA, Marks V. Radioimmunoassay of gastric inhibitory polypeptide. Ann Clin Biochem 1978; 15: gastric inh

16 Elliott RM, Morgan LM, Tredger JA, Deacon S, Wright J, Marks V. Glucagon-like polypeptide-1 (7-36) amide and glucose dependent insulinotropic polypeptide in response to nutrient ingestion in man: acute postprandial and $24 \mathrm{hr}$ secretion pattern. $\mathcal{F}$ Endocrinol 1993; 138: 159-66.

17 Ensinck JW, D'Alessio DA. The enteroinsular axis revisited: a novel role for an incretin. $N$ Engl $\mathcal{F}$ Med 1992; 326: 1352-3.

18 Randle PJ, Garland RB, Hales CN, Newsholme EA. The glucose-fatty acid cycle. Its role in insulin sensitivity and the metabolic disturbances of diabetes mellitis. Lancet 1963; i: 785-9.

19 Biorntorp P, Bergman H, Varnauskas E. Plasma free fatty acid turnover rate in obesity. Acta Med Scand 1969; 185: 351-6. 